\title{
Degradabilidade ruminal da matéria seca, da fração fibrosa e da proteína bruta de forrageiras
}

\author{
Aureliano José Vieira Pires ${ }^{(1)}$, Ricardo Andrade Reis ${ }^{(2)}$, Gleidson Giordano Pinto de Carvalho(3), \\ Gustavo Rezende Siqueira ${ }^{(2)}$, Thiago Fernandes Bernardes ${ }^{(2)}$, Ana Cláudia Ruggieri(2) \\ Eneida de Oliveira Almeida ${ }^{(2)}$ e Marcella de Toledo Piza Roth ${ }^{(2)}$
}

\begin{abstract}
(1)Universidade Estadual do Sudoeste da Bahia, Dep. de Tecnologia Rural e Animal, Av. Palmeiras, 491, Morumbi, CEP $45700-000$ Itapetinga, BA. E-mail: aureliano@uesb.br (2)Universidade Estadual Paulista, Dep. de Zootecnia, Via de Acesso Prof. Paulo D. Castellane, s/no, CEP 14884-900 Jaboticabal, SP. E-mail: rareis@fcav.unesp.br, siqueiragr@yahoo.com.br, tfbernardes@yahoo.com.br, eneida_oa@yahoo.com.br, marcellaroth@yahoo.com.br (3)Universidade Federal de Viçosa, Dep. de Zootecnia, Campus Universitário, CEP 36570-000 Viçosa, MG. E-mail: giordano113@hotmail.com
\end{abstract}

Resumo - O objetivo deste trabalho foi avaliar a degradabilidade ruminal da matéria seca, da fibra em detergente neutro, da fibra em detergente ácido e da proteína bruta da alfafa (Medicago sativa), aveia-preta (Avena strigosa), leucena (Leucaena leucocephala) e guandu (Cajanus cajan). Amostras de $3 \mathrm{~g}$ das forragens foram incubadas no rúmen de três novilhos por períodos de 0, 6, 12, 24, 36, 48 e 72 horas. As degradabilidades efetivas da matéria seca da alfafa e da aveia, para a taxa de passagem de $5 \%$ por hora, foram elevadas (acima de $60 \%$ ). A leucena e o guandu apresentaram valores inferiores, 50,9 e 56,0\%, respectivamente. A partir de 24 horas de incubação, a aveia se destacou com maior desaparecimento da fibra em detergente neutro e da fibra em detergente ácido, e ainda apresentou as mais elevadas taxas de degradação efetiva destas frações. A aveia foi a forragem que apresentou maior degradabilidade da matéria seca, da fibra em detergente neutro, da fibra em detergente ácido e da proteína bruta no rúmen. $\mathrm{O}$ guandu, entretanto, foi a forragem com as piores taxas de degradação.

Termos para indexação: degradação, forragem, volumosos, rúmen.

\section{Forages dry matter, fibrous fraction and crude protein ruminal degradability}

\begin{abstract}
The objective of this work was to evaluate ruminal degradability of dry matter, neutral detergent fiber, acid detergent fiber and crude protein of alfalfa (Medicago sativa), black oat (Avena strigosa), leucaena (Leucaena leucocephala) and pigeon pea (Cajanus cajan). Samples of $3 \mathrm{~g}$ of forages were incubated in the rumen of three steers for $0,6,12,24,36,48$ and 72 hours periods. The dry matter effective degradabilities of alfalfa and oat, for a passage rate of $5 \%$ /hour, were high (over $60 \%$ ). However, leucaena and pigeon pea showed lower values, 50.9 and 56.0\%, respectively. From 24-hour incubation period on, the oat presented the highest neutral detergent fiber and acid detergent fiber disappearance and showed the greatest effective degradation rates of these fractions. The oat was the forage with the highest dry matter, neutral detergent fiber, acid detergent fiber and crude protein ruminal degradability. Pigeon pea, however, was the forage that showed the worst degradation rates.
\end{abstract}

Index terms: degradation, forage, roughage, rumen.

\section{Introdução}

O Brasil apresenta grande diversidade de plantas forrageiras que são utilizadas na alimentação animal. Muitas delas podem ser estudadas, pela importância que desempenham em sua região. De acordo com Sniffen et al. (1992), os alimentos utilizados nas dietas dos ruminantes devem ser fracionados para sua adequada caracterização.

A cinética de degradação ruminal vem sendo pesquisada em diferentes alimentos, volumosos ou concentrados, utilizados na nutrição de ruminantes. Esse fato tem se mostrado muito útil para os pesquisadores, por contribuir com o balanceamento das dietas e atender às exigências dos microrganismos e do animal hospedeiro (Lucci et al., 1998).

A produtividade animal em regiões tropicais é baixa quando comparada à de regiões temperadas, porque as plantas tropicais produzem grande quantidade de matéria seca com baixo valor nutritivo. Segundo Broderick (1995), normalmente as leguminosas forrageiras apresentam alta taxa de degradação e alta degradabilidade 
dos nutrientes em relação às gramíneas. Dessa forma, como a fonte de proteína para a alimentação animal é um dos fatores mais limitantes da produção, torna-se indispensável o estudo da utilização de forrageiras ricas em proteína e de menor custo.

A degradabilidade das frações fibrosas dos alimentos cresce à medida que a participação de alimentos volumosos na dieta dos animais aumenta (Souza et al., 2000). A composição nutricional dos alimentos produzidos sob condições tropicais é diferente da dos alimentos obtidos em regiões de clima temperado (Van Soest, 1994). De todos os nutrientes necessários às exigências nutricionais para mantença, crescimento e produção de bovinos, a energia oriunda da degradação ruminal de celulose e hemicelulose constitui a principal contribuição dos volumosos (Ítavo et al., 2002). A sincronização entre a degradação ruminal de carboidratos e de proteínas é necessária para determinar as taxas de degradação da matéria seca e das diferentes frações que compõem os carboidratos e as proteínas (Balsalobre et al., 2003).

A técnica in situ permite o contato íntimo do alimento avaliado com o ambiente ruminal, por isso é considerada a melhor forma de simulação desse meio, embora o alimento não esteja sujeito a todos os eventos digestivos, como mastigação, ruminação e passagem. No entanto, estudos das estimativas da degradação ruminal de forrageiras no Brasil fornecem dados que contribuem para a elaboração de uma tabela nacional de composição de alimentos (Veloso et al., 2000; Ruggieri et al., 2001).

Com o surgimento e aprimoramento do programa Cornell (CNCPS) (Russell et al., 1992; Sniffen et al., 1992), uma nova forma de estimar o desempenho animal foi adotada. De acordo com Balsalobre et al. (2003), os programas de predição de desempenho eram estáticos, e não levavam em consideração os vários componentes do alimento com suas diferentes taxas de degradação ruminal e suas interações. Deste modo, a mensuração da degradabilidade no rúmen, sem considerar a taxa de passagem, pode superestimar a extensão da degradação, pois as partículas dos alimentos estão sujeitas à passagem para o compartimento seguinte, antes de serem completamente degradadas (Ladeira et al., 2001).

O objetivo deste trabalho foi avaliar a degradabilidade ruminal da matéria seca, da fibra em detergente neutro, da fibra em detergente ácido e da proteína bruta da alfafa (Medicago sativa), aveia-preta (Avena strigosa), leucena (Leucaena leucocephala) e guandu (Cajanus cajan) em novilhos da raça Nelore.

\section{Material e Métodos}

A incubação ruminal foi realizada no setor de Forragicultura da Unesp, Jaboticabal, utilizando-se três bovinos machos, castrados, da raça Nelore, canulados no rúmen, com peso vivo médio de $200 \mathrm{~kg}$, mantidos durante todo o período experimental em sistema de confinamento, em baias individuais, e alimentados diariamente, com dieta constituída de silagem de milho, alfafa, aveia, leucena e guandu fornecidos ad libitum, e $1 \mathrm{~kg}$ de concentrado à base de milho, farelo de soja e mistura mineral.

As forrageiras utilizadas na incubação ruminal foram: a alfafa (Medicago sativa), apresentando $10 \%$ de florescimento; a aveia-preta (Avena strigosa), 40 dias depois do corte; a leucena (Leucaena leucocephala), parte com ramos e folhas tenros; e o guandu (Cajanus cajan), parte superior com ramos e folhas tenros, cuja composição química-bromatológica está apresentada na Tabela 1 . Todas as forrageiras foram pré-secadas em estufa a $65^{\circ} \mathrm{C}$, moídas em peneiras com crivos de $4 \mathrm{~mm}$ e colocadas em sacos de náilon na quantidade de, aproximadamente, 3,0 g de matéria seca por saco, a fim de manter uma relação próxima de 20 mg de matéria seca por $\mathrm{cm}^{2}$ de área superficial do saco. Os períodos de incubação corresponderam aos tempos de $0,6,12,24,36$, 48 e 72 horas, sendo os sacos colocados em tempos diferentes, para serem retirados todos ao mesmo tem-

Tabela 1. Teores médios de matéria seca (MS), matéria orgânica (MO), proteína bruta (PB), extrato etéreo (EE), fibra em detergente neutro (FDN), fibra em detergente ácido (FDA), hemicelulose, celulose, lignina, cinza e nitrogênio insolúvel em detergente ácido (NIDA) das forrageiras utilizadas na incubação ruminal.

\begin{tabular}{|c|c|c|c|c|}
\hline Item & Alfafa & Aveia & Leucena & Guandu \\
\hline MS (\%) & 20,3 & 12,1 & 26,8 & 26,1 \\
\hline MO (\% MS) & 88,8 & 92,4 & 90,4 & 94,7 \\
\hline PB (\% MS) & 31,9 & 26,3 & 32,6 & 22,4 \\
\hline $\mathrm{EE}(\% \mathrm{MS})$ & 2,2 & 2,0 & 4,9 & 4,5 \\
\hline FDN (\% MS) & 52,3 & 58,4 & 75,9 & 73,6 \\
\hline FDA (\% MS) & 43,5 & 44,1 & 61,9 & 58,4 \\
\hline Hemicelulose (\% MS) & 8,8 & 14,3 & 14,0 & 15,2 \\
\hline Celulose (\% MS) & 33,2 & 34,0 & 48,3 & 42,1 \\
\hline Lignina (\% MS) & 7,9 & 7,1 & 11,9 & 12,1 \\
\hline Cinza (\% MS) & 11,2 & 7,6 & 9,6 & 5,3 \\
\hline $\mathrm{NIDA}^{(1)}$ & 8,5 & 8,3 & 12,2 & 20,2 \\
\hline
\end{tabular}

${ }^{(1)}$ Em porcentagem do $\mathrm{N}$ total. 
po, promovendo, dessa forma, lavagem uniforme do material por ocasião da retirada do rúmen.

Retirados do rúmen, os sacos foram imediatamente imersos em água fria e posteriormente lavados, manualmente, em água corrente, até que esta escorresse límpida e, então, colocados para secar em estufa de ventilação forçada de ar a $65^{\circ} \mathrm{C}$, onde permaneceram por 48 horas. Logo depois, foram pesados para determinação do desaparecimento da matéria-seca no rúmen. As análises dos valores de matéria seca (MS), fibra em detergente neutro (FDN), fibra em detergente ácido (FDA) e proteína bruta (PB), dos resíduos pós-digestão ruminal foram realizadas segundo método descrito por Silva \& Queiroz (2002).

Os dados de degradabilidade in situ da matéria seca (DISMS), da fibra em detergente neutro (DIFDN), da fibra em detergente ácido (DIFDA) e da proteína bruta (DIPB) foram obtidos pela diferença de peso, encontrada entre as pesagens efetuadas antes e depois da incubação ruminal, e expressos em porcentagem. Foi utilizado o modelo de Ørskov \& McDonald (1979) para a degradabilidade potencial de cada forrageira, de acordo com o modelo: $\mathrm{p}=\mathrm{a}+\mathrm{b}\left(1-\mathrm{e}^{-\mathrm{ct}}\right)$, em que $\mathrm{p}$ é a degradabilidade potencial; a é a fração solúvel em água; b é a fração insolúvel em água, mas potencialmente degradável; e c é a taxa de degradação da fração b. $\mathrm{Na}$ degradabilidade efetiva, foi utilizado o modelo: $\mathrm{DE}=\mathrm{a}+(\mathrm{bc}) /(\mathrm{c}+\mathrm{k})$, em que DE é a degradabilidade efetiva, e k é a taxa de passagem de partículas no rúmen.

Foi estimada a degradabilidade efetiva da MS, da FDN, da FDA e da PB de cada forrageira, levando-se em conta as taxas de passagem de 2, 5 e $8 \%$ por hora, as quais correspondem aos níveis de ingestão alimentar baixo, médio e alto, respectivamente, segundo preconizado pelo Agricultural Research Council (1984).

Foi aplicado o teste de Tukey a 5\% de probabilidade para comparar as médias de degradabilidade da MS, da FDN, da FDA e da PB de acordo com os períodos de incubação, utilizando o programa SAEG versão 8.0 (UFV, 1998).

\section{Resultados e Discussão}

Ao comparar a degradabilidade da matéria seca (MS) das forrageiras em função dos períodos de incubação, verificou-se predominância da aveia, em todos os tempos, seguidos da alfafa, da leucena e do guandu (Figura 1). O maior desaparecimento ruminal da MS da aveia no tempo zero ocorreu, provavelmente, devido à maior presença de compostos solúveis em água em relação às demais forrageiras. A partir do período de in- cubação de 36 horas, houve tendência de a degradabilidade da MS de todas as forrageiras manterse constante. A diferença na degradação final (72 horas) pode ter sido influenciada pela quantidade de parede celular apresentada nas forrageiras, pois o teor de fibra em detergente neutro (FDN) variou, sendo encontrado valores de 52,3, 58,4, 85,9 e 73,6\%, respectivamente, na alfafa, aveia, leucena e guandu.

Na fração FDN, a aveia se destacou com maior degradação, estabilizando-se a partir das 36 horas de incubação, com taxa de desaparecimento ruminal de aproximadamente $83 \%$. Na análise estatística, a aveia e a leucena apresentaram valores diferentes de degradação, entretanto ambas as forragens estabilizaram o desaparecimento da FDN a partir das 24 horas de incubação ruminal, com taxas de degradação entre 60 e $88 \%$ (Figura 2). Para Mertens (1997), o enchimento ruminal é um fator limitante de consumo, pois, quanto maior for a ingestão de FDN, menor será a taxa de passagem do alimento. O consumo de alimento está correlacionado negativamente com a FDN, ou seja, quanto menos degradável, mais tempo permanecerá a forragem no rúmen, e conseqüentemente, mais o enchimento limitará a ingestão de volumosos.

De maneira semelhante à degradabilidade da MS e FDN, o desaparecimento ruminal da fibra em detergente ácido (FDA) da aveia foi superior ao das demais forrageiras (Figura 3). No maior tempo de incubação ruminal, 72 horas, a alfafa e a leucena apresentaram degradabilidades semelhantes, 64,9 e 64,1\%, respectivamente, enquanto o guandu apresentou o menor valor, $58,5 \%$. Embora o guandu tenha apresentado a menor taxa de degradabilidade da FDN (61,5\%) e da FDA

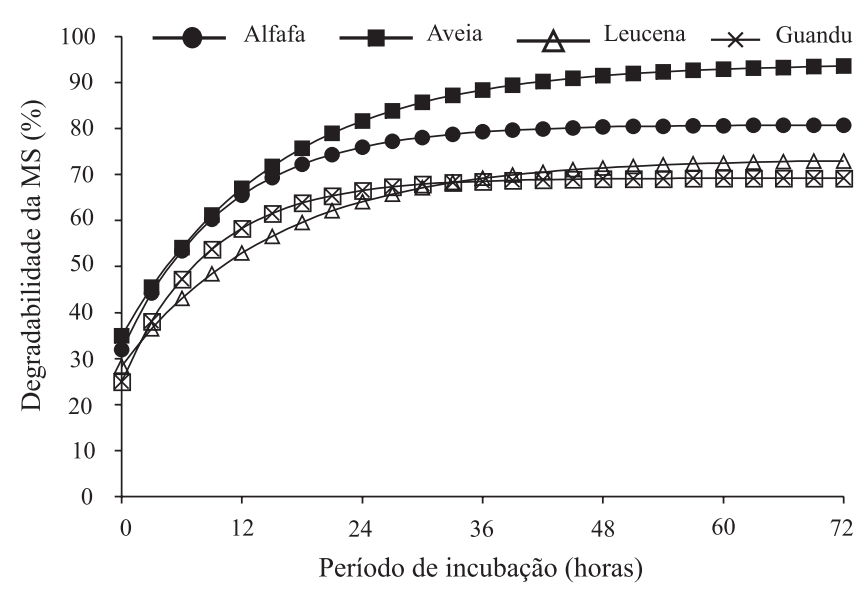

Figura 1. Degradabilidade da matéria seca (MS) de diferentes forrageiras em função do período de incubação no rúmen de novilhos Nelore. 
(58,5\%), no maior tempo de incubação, esses valores são considerados satisfatórios, pois, de todos os nutrientes necessários para a mantença, o crescimento e a produção de bovinos, a energia oriunda da degradação ruminal dos carboidratos estruturais (fibrosos) constitui a principal contribuição dos volumosos (Ítavo et al., 2002).

Alimentos produzidos sob condições tropicais apresentam composição nutricional diferente dos alimentos obtidos em regiões de clima temperado (Van Soest, 1994). A degradação da FDA está intimamente ligada à digestibilidade dos alimentos e, portanto, o seu aproveitamento ou a sua degradação será maior ou menor de acordo com sua composição, já que a lignina presente na FDA não é aproveitada (Silva \& Queiroz, 2002).

As características de degradação da PB (Tabelas 2 e 3) mostraram a mesma tendência da MS.

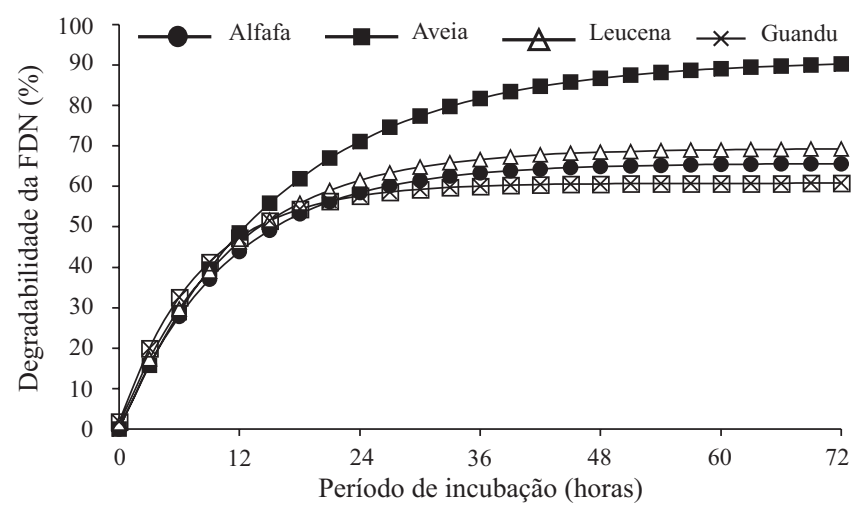

Figura 2. Degradabilidade da fibra em detergente neutro (FDN) de diferentes forrageiras em função do período de incubação no rúmen de novilhos Nelore.

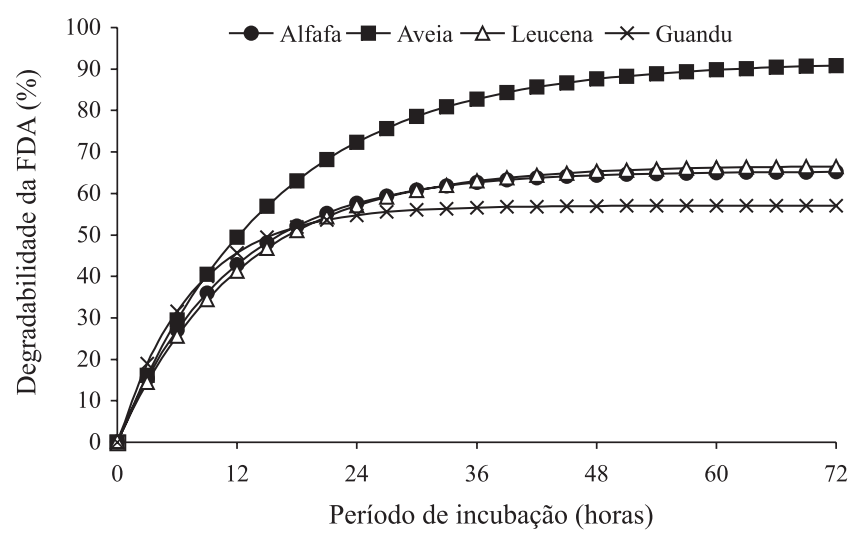

Figura 3. Degradabilidade da fibra em detergente ácido (FDA) de diferentes forrageiras em função do período de incubação no rúmen de novilhos Nelore.
Isso significa que mais proteína escaparia da degradação ruminal na leucena, seguida pelo guandu, pela alfafa e pela aveia. A degradabilidade potencial da PB da aveia alcançou quase $100 \%$. Em seguida, o maior potencial de degradabilidade da PB foi verificado em alfafa, seguida pelo guandu e pela leucena. Estas diferenças na degradabilidade podem ser atribuídas a diferenças nas características específicas da proteína, à sua acessibilidade às enzimas digestivas, ou à presença de substâncias anti-nutricionais. Estas substâncias, em particular os taninos e outros polifenóis, os quais protegem a proteína e a celulose da degradação ruminal (Van Soest, 1994), estão presentes em quantidades apreciáveis nas folhas de leguminosas arbustivas, como a leucena e o guandu.

Os coeficientes de degradação da MS, FDN, FDA e PB da fração solúvel em água (a), da fração insolúvel em água, mas potencialmente degradável (b), e a taxa de degradação de b (\% por hora), encontram-se na Tabela 2 .

A alfafa e a aveia destacaram-se com maior fração solúvel em água quanto à MS. Por sua vez, a leucena e o guandu apresentaram valores inferiores, entre 25 e $28 \%$. Quanto à fração solúvel em água da FDN e da FDA, os valores aproximaram-se de zero. Na avaliação da degradabilidade ruminal da silagem de sorgo, Molina

Tabela 2. Parâmetros da degradação ruminal da matéria seca (MS), da fibra em detergente neutro (FDN), da fibra em detergente ácido (FDA) e da proteína bruta (PB) das forrageiras incubadas no rúmen, usando a equação não linear $\mathrm{p}=\mathrm{a}+$ $\mathrm{b}\left(1-\mathrm{e}^{-\mathrm{ct}}\right)$.

\begin{tabular}{lcccc}
\hline Forrageira & \multicolumn{3}{c}{ Parâmetros $^{(1)}$} & $\mathrm{R}^{2}$ \\
\cline { 2 - 3 } & $\mathrm{a}$ & $\mathrm{b}$ & $\mathrm{c}$ \\
Alfafa & 32,0 & \multicolumn{4}{c}{ Degradabilidade da MS } \\
Aveia & 35,0 & 48,8 & 0,096 & 98,6 \\
Leucena & 28,3 & 59,1 & 0,065 & 95,4 \\
Guandu & 25,0 & 45,0 & 0,066 & 99,4 \\
\hline & \multicolumn{4}{c}{ Degradabilidade da FDN } \\
Alfafa & 0,0 & 65,7 & 0,092 & 97,5 \\
Aveia & 0,0 & 91,2 & 0,063 & 98,3 \\
Leucena & 1,2 & 68,1 & 0,090 & 99,7 \\
Guandu & 1,9 & 58,9 & 0,123 & 93,6 \\
\hline & \multicolumn{4}{c}{ da } \\
Alfafa & 0,1 & 65,2 & 0,089 & 99,6 \\
Aveia & 0,0 & 91,7 & 0,065 & 99,4 \\
Leucena & 0,3 & 66,5 & 0,080 & 97,9 \\
Guandu & 0,5 & 57,0 & 0,134 & 99,2 \\
\hline \multirow{3}{*}{ Alfafa } & 40,9 & Degradabilidade da PB & \\
Aveia & 44,0 & 54,0 & 0,133 & 98,4 \\
Leucena & 33,2 & 53,9 & 0,096 & 98,2 \\
Guandu & 30,8 & 53,6 & 0,061 & 95,9 \\
\hline
\end{tabular}

(1)a: fração solúvel em água, b: fração insolúvel em água, mas potencialmente degradável, c: taxa de degradação da fração b. 
et al. (2002) relataram valores de 23 e $21,1 \%$ para a fração solúvel em água da FDN e FDA, respectivamente. Estes valores são considerados altos e, são superiores aos encontrados neste trabalho (Tabela 2).

Quanto ao coeficiente b da MS, o maior valor encontrado foi em aveia. Nas demais forrageiras, essa taxa foi menor, sem grandes variações. Quanto à FDN e FDA, o mesmo comportamento foi observado, sendo que a aveia apresentou mais de $90 \%$ de fração potencialmente degradável. Por sua vez, a alfafa e a leucena apresentaram valores intermediários variando de 60 a $68 \%$, e o guandu, os menores valores, entre 50 e $60 \%$. Embora o guandu tenha apresentado as taxas mais baixas de a e de b, apresentou o maior valor de c, que é a taxa de degradação de $b$ em porcentagem por hora, tanto para a MS como para a FDN e a FDA. Assim, apesar de possuir um potencial menor de degradação, o guandu possui excelente taxa de degradabilidade da fração b, entre 11 e $13 \%$.

Os valores de degradabilidade potencial (DP) e efetiva (DE) da alfafa, aveia, leucena e guandu estão apresentados na Tabela 3. A DE foi estimada considerando as taxas de passagem de 2,5 e $8 \%$ por hora. A mensuração da degradabilidade no rúmen, sem considerar a taxa de passagem, pode superestimar a extensão da degradação, pois as partículas dos alimentos es-

Tabela 3. Degradabilidade potencial (DP) e efetiva (DE) da matéria seca (MS), da fibra em detergente neutro (FDN), da fibra em detergente ácido (FDA) e da proteína bruta (PB) das forrageiras, calculadas para taxas de passagem de 2, 5 e $8 \%$ por hora.

\begin{tabular}{lcccc}
\hline Componente & DP & \multicolumn{3}{c}{ DE (taxa de passagem em \%/h) } \\
\cline { 3 - 5 } & \multicolumn{5}{c}{2} & Alfafa \\
\hline & & 72,4 & 64,1 & 58,7 \\
MS & 80,8 & 54,0 & 42,6 & 35,1 \\
FDN & 65,7 & 53,3 & 41,9 & 34,4 \\
FDA & 65,3 & 87,8 & 80,2 & 74,6 \\
PB & 94,9 & \multicolumn{5}{c}{ Aveia } \\
MS & 94,0 & 80,2 & 68,4 & 61,5 \\
FDN & 91,0 & 69,2 & 50,9 & 40,2 \\
FDA & 91,5 & 70,0 & 51,7 & 41,0 \\
PB & 97,8 & 88,6 & 79,4 & 73,4 \\
\hline & \multicolumn{5}{c}{ Leucena } \\
MS & 73,3 & 62,9 & 53,9 & 48,7 \\
FDN & 69,3 & 57,0 & 45,0 & 37,3 \\
FDA & 66,7 & 53,4 & 41,2 & 33,5 \\
PB & 86,1 & 73,6 & 62,7 & 56,4 \\
\hline & 69,2 & 62,8 & 55,9 & 51,2 \\
MS & 60,8 & 52,5 & 43,8 & 37,6 \\
FDN & 57,5 & 50,1 & 42,0 & 36,2 \\
FDA & 89,4 & 81,0 & 72,2 & 65,9 \\
PB & \multicolumn{5}{c}{ Guandu } \\
\hline
\end{tabular}

tão sujeitas à passagem para o compartimento seguinte, antes de serem completamente degradadas. Quanto à DE da MS, as forragens alfafa e aveia apresentaram degradabilidades semelhantes entre si e superiores em relação à leucena e ao guandu. A maior DP obtida foi para a aveia.

Quanto à DE da FDN e da FDA, as forrageiras alfafa, leucena e guandu apresentaram valores aproximados, independentemente da taxa de passagem. Contudo, a aveia se destacou com maiores valores. Na DP, o mesmo comportamento foi observado: a aveia apresentou mais de $90 \%$ de DP, enquanto a alfafa, leucena e guandu alcançaram valores entre 50 e 70\%. Quanto à DP da PB, a aveia destacou-se, seguida pela alfafa, pelo guandu e pela leucena, que apresentou menor potencial.

A DP da FDN de 72\% e 70,46\% para o feno de coastcross, relatadas por Lucci et al. (1998) e Rodrigues et al. (2000), respectivamente, foram semelhantes ao valor obtido em leucena neste trabalho. Esses valores são inferiores ao obtido para a aveia, entretanto, essas variações obtidas na degradabilidade das frações fibrosas, em sua maioria, estão relacionadas com o teor e a constituição da fibra presente no alimento.

Ao examinar o comportamento da degradabilidade da MS, da FDN, da FDA e da PB em função do tempo de incubação (Figuras 1, 2, 3 e 4), observa-se que a aveia apresentou um comportamento superior, seguida pela alfafa, que, por sua vez, foi superior à leucena e ao guandu, que apresentaram comportamento semelhante. Esses comportamentos provavelmente ocorreram em

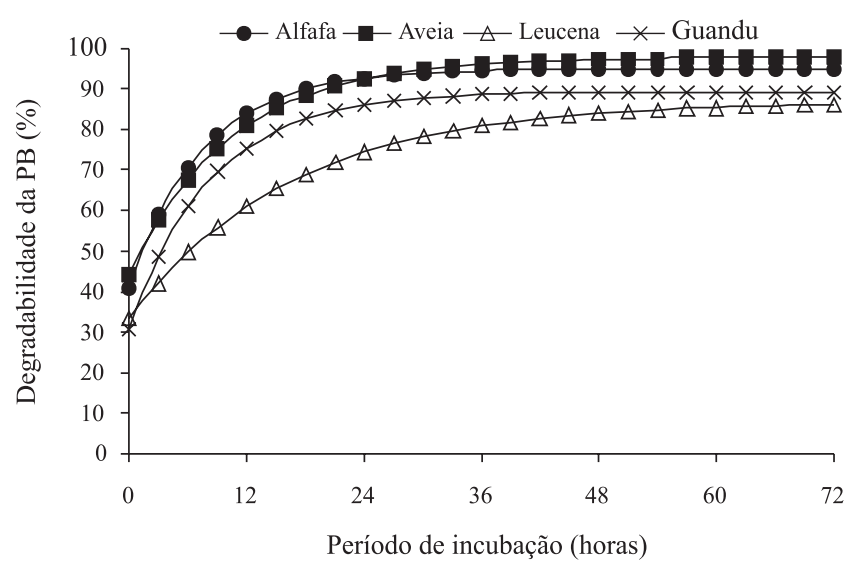

Figura 4. Degradabilidade da proteína bruta (PB) de diferentes forrageiras em função do período de incubação no rúmen de novilhos Nelore. 
função da melhor qualidade apresentada pela aveia (gramínea temperada) e pela alfafa (leguminosa com caules tenros), quando comparadas à leucena e ao guandu, leguminosas tropicais com caules mais fibrosos.

\section{Conclusões}

1. A aveia-preta apresenta melhores coeficientes de degradabilidade potencial e efetiva da matéria seca, da fibra em detergente neutro, da fibra em detergente ácido e da proteína bruta no rúmen, em relação aos da alfafa, leucena e guandu.

2. Após o período de incubação de 36 horas, as curvas de degradação apresentam tendência constante, mostrando o potencial de degradação de matéria seca de cada forrageira.

3. O guandu apresenta taxas de degradação inferiores às de aveia-preta, alfafa e leucena.

\section{Referências}

AGRICULTURAL RESEARCH COUNCIL (Londres, Inglaterra). The nutrient requirements of ruminant livestock. London: Commonwealth Agricultural Bureaux, 1984. 45p.

BALSALOBRE, M.A.A.; CORSI, M.; SANTOS, P.M.; PENATI, M.A.; DEMETRIO, C.G.B. Cinética da degradação ruminal do capim Tanzânia irrigado sob três níveis de resíduo pós-pastejo. Revista Brasileira de Zootecnia, v.32, p.1747-1762, 2003.

BRODERICK, G.A. Desirable characteristics of forage legumes for improving protein utilization in ruminants. Journal of Animal Science, v.73, p.2760-2773, 1995.

ÍTAVO, L.C.V.; VALADARES FILHO, S. de C.; SILVA, F.F. da; VALADARES, R.F.D.; CECON, P.R.; ÍTAVO, C.C.B.F.; MORAES, E.H.B.K. de; PAULINO, P.V.R. Consumo, degradabilidade ruminal e digestibilidade aparente de fenos de gramíneas do gênero Cynodon e rações concentradas utilizando indicadores internos. Revista Brasileira de Zootecnia, v.31, p.1024-1032, 2002.

LADEIRA, M.M.; RODRIGUEZ, N.M.; GONÇALVES, L.C.; BORGES, I.; BENEDETTI, E.; BRITO, S.C.; SÁ, L.A.P. Cinética ruminal do feno de Stylosanthes guianensis. Arquivo Brasileiro de Medicina Veterinária e Zootecnia, v.53, p.1-8, 2001.

LUCCI, C. de S.; MELOTTI, L.; KODAIRA, V.; CASTRO, A.L. de; RODRIGUES, P.H.M. Degradabilidade ruminal de alimentos em vacas secas e lactantes, recebendo $70 \%$ ou $50 \%$ de MS das rações como volumosos. Brazilian Journal of Veterinary Research and Animal Science, v.35, p.127-133, 1998.
MERTENS, D.R. Creating a system for meeting the fiber requirements of dairy cows. Journal of Dairy Science, v.80, p.14631481, 1997.

MOLINA, L.R.; GONÇALVES, L.C.; RODRIGUEZ, N.M.; RODRIGUES, J.A.S.; FERREIRA, J.J.; CASTRO NETO, A.G. Digestibilidade in situ das frações fibrosas de silagens de seis genótipos de sorgo (Sorghum bicolor (L.) Moench) em diferentes estádios de maturação. Arquivo Brasileiro de Medicina Veterinária e Zootecnia, v.54, p.169-179, 2002.

$\varnothing$ RSKOV, E.R.; McDONALD, I. The estimation of protein degradability in the rumen from incubation measurements weighted according to rate of passage. Journal of Agricultural Science, v.92, p.499-503, 1979.

RODRIGUES, P.H.M.; LUCCI, C. de S.; MELOTTI, L. Efeitos da lasalocida sódica e proporção volumoso/concentrados sobre a degradabilidade in situ do farelo de soja e do feno Coast-cross [Cynodon dactylon (L.) Pers.] em vacas secas. Brazilian Journal of Veterinary Research and Animal Science, v.37, p.127-133, 2000.

RUGGIERI, A.C.; TONANI, F.L.; ANDRADE, P.; SILVEIRA, A.C. Efeito do emurchecimento e da adição de fubá na degradabilidade in situ da silagem de alfafa (Medicago sativa L.). Arquivo Brasileiro de Medicina Veterinária e Zootecnia, v.53, p.94-99, 2001.

RUSSELL, J.B.; O’CONNOR, J.D.; FOX, D.G.; VAN SOEST, P.J.; SNIFFEN, C.J.A net carbohydrate and protein system for evaluating cattle diets: I. Ruminal fermentation. Journal of Animal Science, v.70, p.3551-3561, 1992.

SILVA, D.J.; QUEIROZ, A.C. de. Análise de alimentos: métodos químicos e biológicos. Viçosa: UFV, 2002. 235p.

SNIFFEN, C.J.; O’CONNOR, J.D.; VAN SOEST, P.J.; FOX, D.G.; RUSSELL, J.B. A net carbohydrate and protein system for evaluating cattle diets: II. Carbohydrate and protein availability. Journal of Animal Science, v.70, p.3562-3577, 1992.

SOUZA, N.H. de; FRANZOLIN, R.; RODRIGUES, P.H.M.; CLARO, GR. del. Efeitos de níveis crescentes de fibra em detergente neutro na dieta sobre a digestão ruminal em bubalinos e bovinos. Revista Brasileira de Zootecnia, v.29, p.1565-1577, 2000.

UFV. Sistema de análises estatísticas e genéticas - SAEG: manual do usuário. Versão 8.0. Viçosa, 1998. 150p.

VAN SOEST, P.J. Nutritional ecology of the ruminant. $2^{\text {nd }} e d$. Ithaca: Cornell University Press, 1994. 476p.

VELOSO, C.M.; RODRIGUEZ, N.M.; SAMPAIO, I.B.M.; GONÇALVES, L.C.; MOURÃO, G.B. pH e amônia ruminais, relação folhas:hastes e degradabilidade ruminal da fibra de forrageiras tropicais. Revista Brasileira de Zootecnia, v.29, p.871-879, 2000.

Recebido em 2 de fevereiro de 2005 e aprovado em 1ㅇ de novembro de 2005 